\title{
Images
}

\section{One bridge too far-an unsuspected aspiration}

\author{
Joel D. Cohen, $\mathrm{MD}^{*}{ }^{\dagger}$; Ami Schattner, $\mathrm{MD}^{*{ }^{\dagger}}$
}

Dyspnea, in particular, when it occurs in elderly patients with multiple morbidities, may have many causes. Sometimes, a little considered cause may be revealed by heightened awareness and a good look at the plain X-rays.

A 50-year-old male with severe Parkinson's disease presented with acute onset of shortness of breath. No stridor was noted. An initial chest X-ray was read as normal. He continued to deteriorate and was intubated without event and with no foreign body seen. On a follow-up chest X-ray, a foreign body in the lower neck was suspected (Figure 1A) and confirmed by a lateral neck film (see Figure 1B). The patient's wife then noticed that his dental bridge had been missing. It was recovered uneventfully from the hypopharynx with a direct laryngoscope. No damage to the soft tissues was noted. Apparently, the foreign object, which had lodged in the posterior recess of the pharynx, had caused increased secretions leading to aspiration and subsequent dyspnea.

Competing interests: None identified

Keywords: Dyspnea, differential diagnosis, upper airway, obstruction of, geriatrics, aspiration
(A)

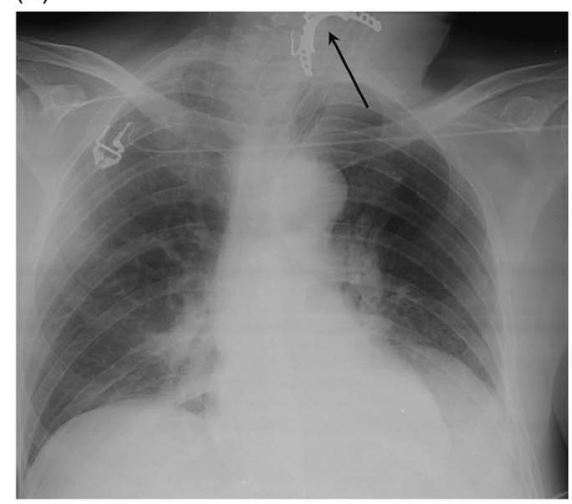

(B)

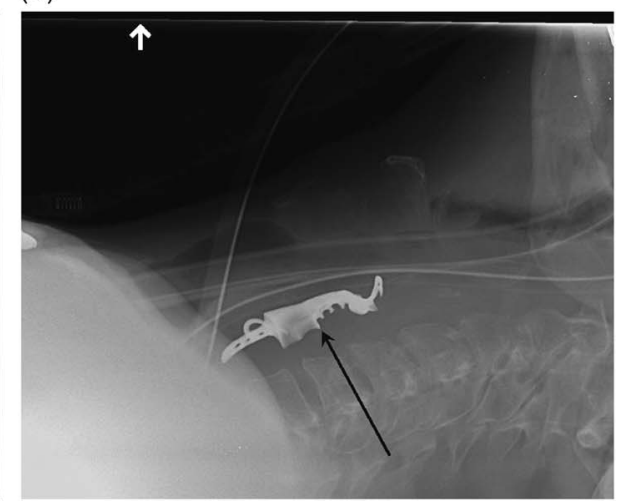

Figure 1. A) Supine chest X-ray, showing a metallic foreign body (dental bridge, arrow) imposed over the neck. Note the endotracheal tube in place. B) Supine lateral neck X-ray with horizontal beam, showing the foreign body posterior to the endotracheal and nasogastric tubes, in the hypopharynx.

From the *Department of Medicine, Kaplan Medical Center, Rehovot; and †Faculty of Medicine, Hebrew University and Hadassah Medical School, Jerusalem, Israel

Correspondence to: Dr. Ami Schattner, Department of Medicine, Kaplan Medical Center, POB 1, Rehovot 76100, Israel; Email: amischatt@ gmail.com 